\title{
Follicular lymphoma-like B cells in healthy individuals: a novel intermediate step in early lymphomagenesis
}

\author{
Sandrine Roulland, ${ }^{1,2,3}$ Jean-Marc Navarro, ${ }^{1,2,3}$ Pierre Grenot, ${ }^{1,2,3}$ \\ Michèle Milili,, 1,2,3 Julie Agopian, ,2,3 Bertrand Montpellier, ${ }^{1,2,3}$ \\ Pascal Gauduchon, ${ }^{4}$ Pierre Lebailly, ${ }^{4,5}$ Claudine Schiff, $, 2,3$ \\ and Bertrand Nadel ${ }^{1,2,3}$
}

\author{
'Centre d'Immunologie de Marseille-Luminy, Université de la Méditerranée, 13288 Marseille, France \\ ${ }^{2}$ Institut National de la Santé et de la Recherche Médicale (INSERM), U631, 13288 Marseille, France \\ ${ }^{3}$ Centre National de la Recherche Scientifique (CNRS), UMR6102, 13288 Marseille, France \\ ${ }^{4}$ Groupe Régional d'Etudes sur le Cancer EA1772, Université de Caen Basse-Normandie, CLCC François BACLESSE, \\ 14076 Caen, France \\ ${ }^{5}$ Registre général des tumeurs du Calvados, CLCC François BACLESSE, 14076 Caen, France
}

Follicular lymphoma is one of the most common adult lymphoma, and remains virtually incurable despite its relatively indolent nature. $t(14 ; 18)(q 32 ; q 21)$ translocation, the genetic hallmark and early initiating event of follicular lymphoma (FL) pathogenesis, is also present at low frequency in the peripheral blood of healthy individuals. It has long been assumed that in healthy individuals $t(14 ; 18)$ is carried by circulating quiescent naive $B$ cells, where its oncogenic potential would be restrained. Here, we question this current view and demonstrate that in healthy individuals, $t(14 ; 18)$ is actually carried by an expanding population of atypical B cells issued from germinal centers, displaying genotypic and phenotypic features of $F L$, and prone to constitute potent premalignant $F L$ niches. These findings strongly impact both on the current understanding of disease progression and on the proper handling of $t(14 ; 18)$ frequency in blood as a potential early biomarker for lymphoma.

\begin{abstract}
CORRESPONDENCE
Bertrand Nadel:

nadel@ciml.univ-mrs.fr

Abbreviations used in this paper: CSR, class-switch recombination; FL, follicular lymphoma; GC, germinal center; HI, healthy individuals; IGH, immunoglobulin heavy chain; LR-PCR, long-range PCR; SHM, somatic hypermutation.
\end{abstract}

The $\mathrm{t}(14 ; 18)(\mathrm{q} 32 ; \mathrm{q} 21)$ translocation results from a mistake of $\mathrm{V}(\mathrm{D}) \mathrm{J}$ recombination and juxtaposes the BCL2 protooncogene with the nonexpressed immunoglobulin heavy chain (IGH) allele (1). As a consequence, the BCL2 gene comes under the control of the IGH enhancer, causing deregulated expression of the antiapoptotic BCL2 protein. Although $t(14 ; 18)$ and ectopic BCL2 expression constitute the initial events of follicular lymphoma (FL) pathogenesis, further B cell differentiation and additional events are clearly required for malignant transformation (2-4). However, early steps of disease progression are still unclear. The presence of the translocation in peripheral blood from healthy individuals (HI) at an average rate of $0,1-10$ cell every million $(5-7)$ led to the hypothesis that $\mathrm{t}(14 ; 18)$ is carried by resting naive $\mathrm{B}$ cells. In such cells, BCL2 oncogenic potential would be restrained,

The online version of this article contains supplemental material. partly because of the fact that they express BCL2 physiologically. Intriguingly, we recently reported that in absence of manifest clinical lymphoma, clonotypic $\mathrm{t}(14 ; 18)^{+}$cells can persist over a 3 -yr period in the peripheral blood from HI (8). As peripheral blood contains a mixture of naive and memory B cells, this unexpected finding led us to question the current model of FL pathogenesis and characterize further such long-lived $\mathrm{t}(14 ; 18)^{+}$clones.

\section{RESULTS AND DISCUSSION}

As a first approach, we sought to determine if $\mathrm{t}(14 ; 18)^{+}$cells in HI are indeed naive B cells by assessing their class-switch recombination (CSR) status. CSR is a hallmark of the germinal center (GC) reaction and is absent in naive cells. To characterize rare $\mathrm{t}(14 ; 18)^{+}$cells out of the bulk of normal cells, we took advantage of their unique BCL2/IGH translocation signature. Indeed, the BCL $2 / \mathrm{J}_{\mathrm{H}}$ fusion does not prevent CSR occurring on the downstream 


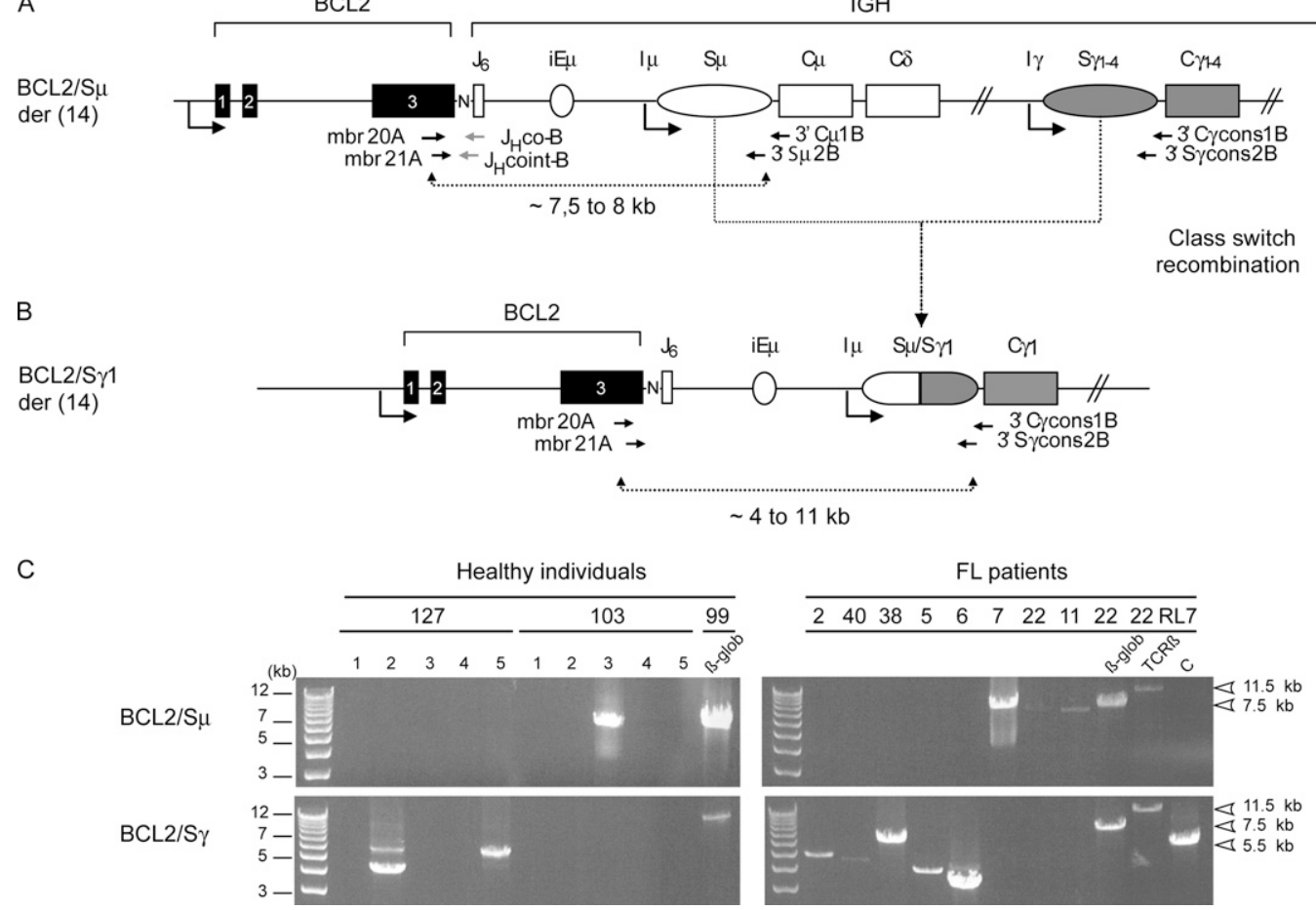

Figure 1. Most $\mathrm{t}(14 ; 18)$ translocations in $\mathrm{HI}$ are associated with CSR. The translocation region (here with a $\mathrm{mbr} / \mathrm{J}_{H} 6$ breakpoint) on the $\operatorname{der}(14)$ chromosome is depicted with either an unswitched (A) or a switched (B) configuration. PCR primers are indicated. Reverse $3^{\prime} \mathrm{C} / \mathrm{S} \gamma$ primers are consensus for the $4 \gamma$ isotypic subclass regions $\left(C \gamma_{1-4} / S \gamma_{1-4}\right)$. The sizes of the $B C L 2 / S \mu$ amplicons are expected to range from 7.5 to $8 \mathrm{~kb}$, depending on BCL2 breakpoints. As CSR is imprecise and can occur anywhere in the $\sim 3 \mathrm{~kb} S \mu$ and $S \gamma$ recombination sites (29), $\mathrm{BCL} 2 / \mathrm{S} \gamma$ amplicon sizes are expected to range from 4 to $11 \mathrm{~kb} . \mathrm{N}, \mathrm{N}$ nucleotides present in the $B C L 2 / J_{H}$ junction; ovals, switch regions upstream of each constant region (except $\mathrm{C} \delta$ ). (C) BCL2/S $\mu$ (top) and BCL2/S $\gamma$ (bottom) LR-PCR from two of the six HI (\#127, \#103; left) and from 8 of the $30 \mathrm{FL}$ patients (right) are shown. 23 out of $30 \mathrm{FL}$ samples underwent CSR to $C \gamma$ (not depicted). Given the low $t(14 ; 18)$ frequency level in $\mathrm{HI}$, a two-step fluctuation nested LR-PCR assay was used, consisting of at least five parallel replicates per sample (left, lanes 1-5). In the fluctuation range, at most one target molecule is present per PCR

constant region of the IGH locus $(9,10)$, and frequency above $10^{-5}$ (Table I, BCL2/J $\mathrm{J}_{\mathrm{H}}$ ) were selected from our previous cohort of $\mathrm{HI}(8)$, and two separate LR-PCR reactions were conducted: one designed to amplify the unswitched BCL2/S $\mu$ region, and the other to amplify switched BCL2/ Sy regions (Fig.1). Results show that only two out of six individuals were found positive for BCL2/S $\mu$, whereas five out of six were positive for BCL2/Sy (Fig. $1 \mathrm{C}$, left, and Table I). Accordingly, individual and cumulative ratios of amplicons were significantly higher for BCL2/S $\gamma$ (9:50) than for BCL2/ $\mathrm{S} \mu(2: 55)(\mathrm{P}=0.02)$. In addition, identical $\mathrm{BCL} 2 / \mathrm{J}_{\mathrm{H}}$ junction signatures were found between BCL2/ $\mathrm{J}_{\mathrm{H}}$ and BCL2/S $\gamma$ amplicons, but not with BCL2/S $\mu$ amplicons (Table I, asterisks), indicating that most translocations previously detected in the blood of HI (5-8) are actually switched. Furthermore, replicate, and if so will give rise to a detectable amplicon. The ratio of positive versus negative replicates allows the estimation of the frequency of the target. A standard single round LR-PCR was used for the FL samples (right). The $t(14 ; 18)^{+}$RL7 cell line harbors a S $\gamma 1$-associated $\mathrm{BCL} 2 / \mathrm{J}_{\mathrm{H}} 6 \operatorname{der}(14)$, and was used as positive control for the BCL2/S $\gamma$ amplification $(C+)$ and as negative control for the BCL2/S $\mu(C-)$; PCR amplifications of the $\beta$-globin gene $(\beta$-glob, $7.5 \mathrm{~kb})$ and of a $D \beta 1$ $J \beta 2.7$ germline fragment of the human TCR- $\beta$ locus (TCR- $\beta, 11.5 \mathrm{~kb}$ ) were performed on each sample as controls for LR-PCR. In case \#127, $\mathrm{BCL} 2 / \mathrm{S} \gamma$ amplification gave rise to two different sizes of amplicons. Cloning/sequencing revealed that the two amplicons corresponded to two distinct translocations, indicating the presence of oligo/polyclonality in the switched population. In FL, the differences in PCR intensities are related to the individual $t(14 ; 18)$ frequency, the origin (lymph node, bone marrow, PBMCs), and the conditioning (e.g., paraffin) of the particular samples (28). All positive PCR products were confirmed by cloning/sequencing (unpublished data).

clonal filiations between switched and unswitched cells were found in one sample (\#102), supporting the presence of an active CSR process in the $\mathrm{t}(14 ; 18)^{+}$clones. Altogether, and contrary to previous assumptions, these data clearly show that most peripheral $\mathrm{t}(14 ; 18)^{+}$cells already underwent CSR, and therefore such cells are not naive B cells.

We next assessed if these long-lived $t(14 ; 18)$-bearing B cells in $\mathrm{HI}$ already transited through the GCs. Circulating naive and memory $\mathrm{B}$ cells can be distinguished on the basis of the CD27 cell surface marker and sIg isotypes (11-13). Fresh PBMCs from 10 healthy donors were collected, and $\mathrm{IgD}^{+} /$ $\mathrm{CD}_{2} 7^{-}$naive, $\mathrm{IgD}{ }^{+} / \mathrm{CD} 27^{+}$memory, and $\mathrm{IgD}^{-} / \mathrm{CD} 27^{+}$ switched memory B cell subsets isolated by cell sorting (Fig. 2 A). The occurrence of $t(14 ; 18)$ was then assessed in total PBMCs and in each fraction by the short-range BCL $2 / \mathrm{J}_{\mathrm{H}}$ 
BRIEF DEFINITIVE REPORT

Table I. Analysis of CSR on the $\mathrm{t}(14 ; 18)^{+}$translocated allele in peripheral blood from $\mathrm{HI}$

\begin{tabular}{|c|c|c|c|c|c|c|c|c|c|c|}
\hline \multirow[t]{2}{*}{ Sample } & \multicolumn{3}{|c|}{$\mathrm{BCL} 2 / \mathrm{J}_{\mathrm{H}}{ }^{\mathrm{a}}$} & \multicolumn{3}{|c|}{$\mathrm{BCL} 2 / \mathrm{S} \mu$} & \multicolumn{4}{|c|}{$\mathrm{BCL} 2 / \mathrm{S} \gamma$} \\
\hline & Detection & Ratio & Frequency & Detection & Ratio & Associated $J_{H}$ & Detection & Ratio & Associated $J_{H}$ & Isotype \\
\hline 99 & yes & $11: 30$ & $1.1 \times 10^{-5}$ & no & $0: 10$ & - & yes & $1: 5$ & $J_{H} 6^{*}$ & $\gamma_{1}$ \\
\hline 102 & yes & $23: 30$ & $3.6 \times 10^{-5}$ & yes & $1: 5$ & $J_{H} 5$ & yes & $1: 5$ & $\mathrm{~J}_{\mathrm{H}} 5$ & $\gamma_{1}$ \\
\hline 103 & yes & $14: 30$ & $1.6 \times 10^{-5}$ & yes & $1: 10$ & $J_{H} 6 b$ & no & $0: 10$ & - & - \\
\hline 109 & yes & $12: 30$ & $1.3 \times 10^{-5}$ & no & $0: 10$ & - & yes & $1: 10$ & $J_{H} ?$ & $\gamma_{2}$ \\
\hline 120 & yes & $11: 30$ & $1.1 \times 10^{-5}$ & no & $0: 10$ & - & yes & $2: 10$ & $J_{H} 4^{*}$ & $\gamma_{1}$ \\
\hline \multirow[t]{2}{*}{127} & yes & $23: 30$ & $3.6 \times 10^{-5}$ & no & $0: 10$ & - & yes & $4: 10$ & $J_{H} 6^{*}$ & $\gamma_{2}$ \\
\hline & & & & & & & & & $J_{H} 6^{*}$ & $\gamma_{1}$ \\
\hline Mean & & & $2.1 \times 10^{-5}$ & & & & & & & \\
\hline Total & $6: 6$ & & & $2: 6$ & $2: 55^{b}$ & & $5: 6$ & $9: 50^{b}$ & & \\
\hline
\end{tabular}

aPreviously described in reference 8 Ratio, positive replicates:total replicates.

${ }^{b}$ Cumulative occurrence of BCL2/S $\mu$ junctions, as determined by the Pearson's $\chi^{2}$ test, was significantly lower than BCL2/S $\gamma$ junctions (P $\left.=0.02\right)$.

${ }^{*} \mathrm{BCL} 2 / J_{H}$ junction identical to the one previously found with the $B C L 2 / J_{H} P C R$ assay (8).

PCR assay (Fig. $2 \mathrm{~B}$ and Table II). As a first approach, we pooled data from the two $\mathrm{CD} 27^{+}$memory subsets and examined the overall contribution of naive $\left(\mathrm{CD} 27^{-}\right)$and memory $\left(\mathrm{CD} 27^{+}\right) \mathrm{B}$ cells to the total $\mathrm{t}(14 ; 18)^{+}$frequency calculated as a fraction of CD19 ${ }^{+} \mathrm{B}$ cells (Fig. 2 C). $t(14 ; 18)$ frequencies of CD $19^{+} \mathrm{B}$ cells ranged from $<1 / 10^{5}$ to the unexpectedly high rate of $\sim 1 / 3.500 \mathrm{~B}$ cells in some individuals (Fig. $2 \mathrm{C}$, squares). Strikingly, although the level of naive $\mathrm{t}(14 ; 18)^{+}$cells constantly remained at baseline (Fig. $2 \mathrm{C}$, circles), CD27 ${ }^{+} \mathrm{B}$ cells accounted in a large part for the amplitude of $t(14 ; 18)$ frequencies (Fig. $2 \mathrm{C}$, triangles). This clearly indicates that circulating $\mathrm{t}(14 ; 18)^{+}$clones in $\mathrm{HI}$ are indeed predominantly B cells which transited through the GCs. To determine if the presence of high levels of $\mathrm{t}(14 ; 18)$ in some individuals was caused by a higher incidence of distinct translocations or to the clonal expansion of a given $\mathrm{t}(14 ; 18)^{+} \mathrm{B}$ cell, we cloned and sequenced 55 out of $61 \mathrm{BCL} 2 / \mathrm{J}_{\mathrm{H}}$ fragments from the $\mathrm{CD} 27^{+}$ subset. One major BCL2/ $\mathrm{J}_{\mathrm{H}}$ junction was observed in most individuals (Fig. 2 D, black bars), indicating that only one clone mainly accounted for $\mathrm{t}(14 ; 18)$ frequencies. Remarkably, this data demonstrate that the wide modulation of $\mathrm{t}(14 ; 18)$ frequency in $\mathrm{HI}$ is not caused by the accumulation of clonally unrelated $\mathrm{t}(14 ; 18)$ naive $\mathrm{B}$ cells in some individuals, but rather to the clonal expansion in the GCs of $\mathrm{t}(14 ; 18)^{+} \mathrm{B}$ cells.

To define further the $t(14 ; 18)^{+}$cells, we next examined the repartition of the translocation in the two memory $\mathrm{B}$ cell subsets: the $\mathrm{IgD}^{-} / \mathrm{CD} 27^{+}$switched memory and the $\mathrm{IgD}^{+} /$ $\mathrm{CD} 27^{+}$so-called "IgM memory" (Table II) (11-14). Unexpectedly, the $\operatorname{IgD}^{+} / \mathrm{CD} 27^{+}$subset contained significantly higher rates of translocation, both in terms of prevalence (nine out of nine samples versus six out of nine, $\mathrm{P}=0.05$ ) and frequency (35 versus $14 \%, \mathrm{P}=0.001$ ). This predominance of a surface $\mathrm{IgD} / \mathrm{M}$ and not $\mathrm{IgG}$ in $\mathrm{t}(14 ; 18)^{+}$cells was in apparent contradiction with our previous LR-PCR results, in which switch to $\mathrm{C} \gamma$ was prevalent on the translocated allele (Table I). To investigate reasons underlying this paradox, we performed the BCL2/S $\mu$ and BCL2/S $\gamma$ LR-PCR assays on the fractionated cells from four healthy donor samples
(Fig. 2 E). As expected, CSR happened on both alleles in the $\mathrm{IgD}^{-} / \mathrm{CD} 27^{+}$subset (Fig. $2 \mathrm{~F}$ ). More surprisingly, CSR also frequently occurred on the translocated allele in the predominant $\mathrm{IgD}^{+} / \mathrm{CD} 27^{+}$subset. This is in sharp contrast with the features of the peripheral $\operatorname{IgD}^{+} \mathrm{CD} 27^{+} \operatorname{IgM}$ memory $\mathrm{B}$ cell subset, which is entirely devoid of CSR both on the productive and the nonproductive alleles (Fig. S1, available at http://www.jem.org/cgi/content/full/jem.20061292/DC1) $(12,13)$. It is therefore very likely that the $t(14 ; 18)^{+}$cells are distinct from this subset, albeit superimposed on the basis of the CD27 and IgD markers. Most importantly, the presence of CSR on the nonfunctional, but not on the productive allele is atypical among normal circulating memory B cells. However, this "allelic paradox" stands as a hallmark of FL $(9,10)$. FL derives from follicle center B cells that encountered antigen and are undergoing somatic hypermutation and CSR $(1,15)$. In FL, CSR occurs as frequently on both alleles, but "downstream switch" (e.g., S $\gamma$-to-S $\alpha$ ) happens at unusually high frequency on the productive allele, specifically sparing the $\mathrm{C} \mu$ region from deletion and allowing sIgM/D expression (9). Consequently, despite CSR occurring on both alleles in $>80 \%$ of cases, most FL cases still express a sIgM and only a minority expresses $\operatorname{sigG}$, sIgA, or no sIg (Fig. $1 \mathrm{C}$ ) $(9,10,16)$. This allelic paradox indicates the presence of a selective pressure in favor of sIgM expression on a B cell population that is at the same time permanently driven to switch (9). Together with the presence of $\operatorname{sgM}^{+} \mathrm{B}$ cell follicular hyperplasia in BCL2 transgenic mice $(2,4)$, this atypical feature of $\mathrm{t}(14 ; 18)^{+}$cells both in FL and HI suggests a direct role of BCL2 ectopic expression in the GCs for this selection. Data from BCL2-Tg mice indicate that long-term survival of follicular B lymphocytes in the GC is of key importance for the acquisition of further genetic changes, which in turn favor further cell transformation and progression to disease (17). It is likely that in HI most $\mathrm{t}(14 ; 18)^{+}$cells were similarly rescued by BCL2 from apoptosis and "frozen" at a differentiation stage in which constitutive activation-induced cytidine deaminase expression drives continuous somatic hypermutation 

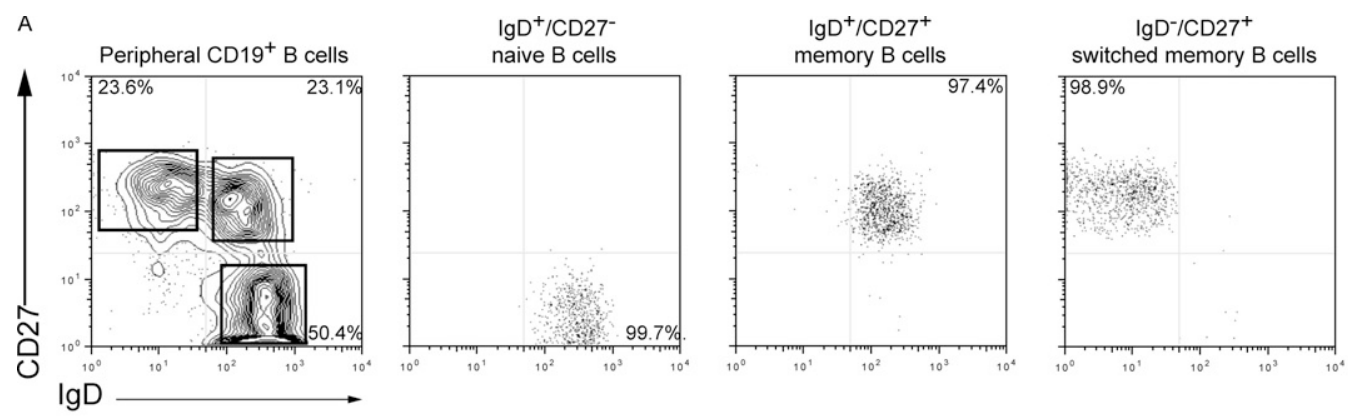

B
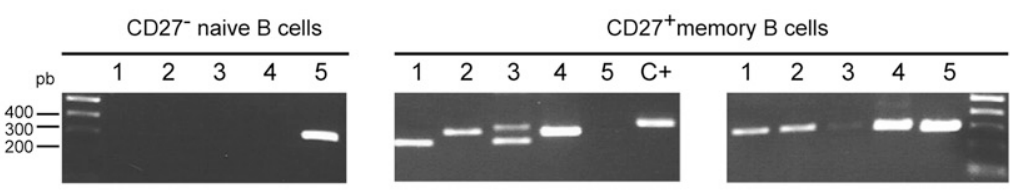

C

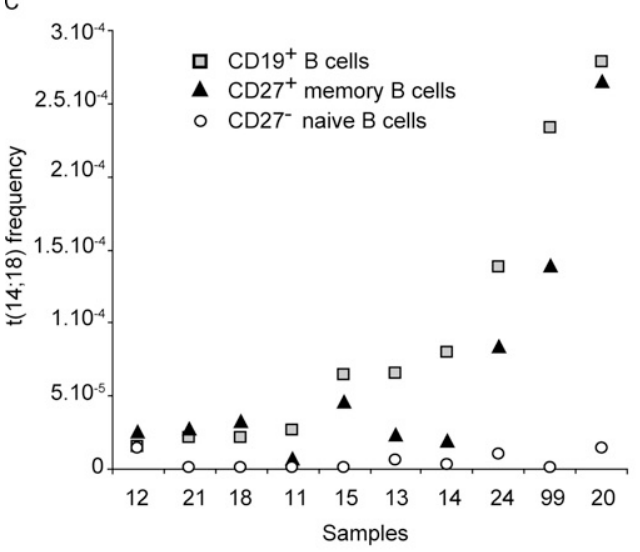

E

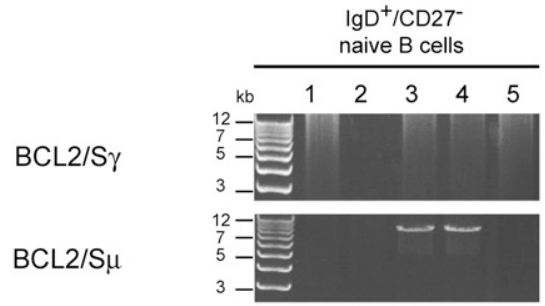

$\mathrm{F}$

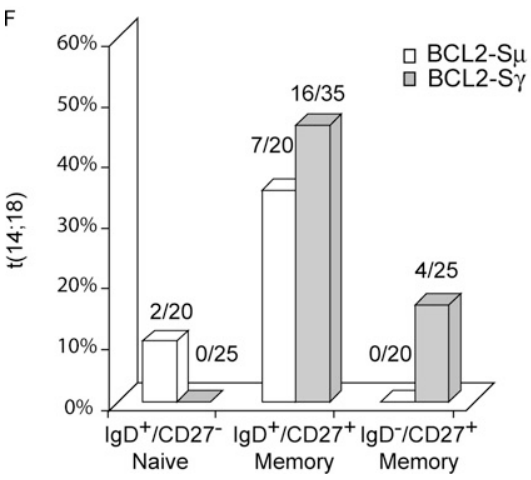

Figure 2. $t(14 ; 18)+B$ cells in the peripheral blood of $\mathrm{HI}$ are not naive $B$ cells and constitute an expanding population of FL-like clones. (A) Human PBMCs from 10 consecutive blood samples were collected from anonymous healthy donors, and $\lg \mathrm{D}^{+} / \mathrm{CD} 27^{-}$naive, $\lg \mathrm{D}^{+} /$ $\mathrm{CD}_{2} 7^{+}$memory, and $\lg \mathrm{D}^{-} / \mathrm{CD} 27^{+}$switched memory B cell populations
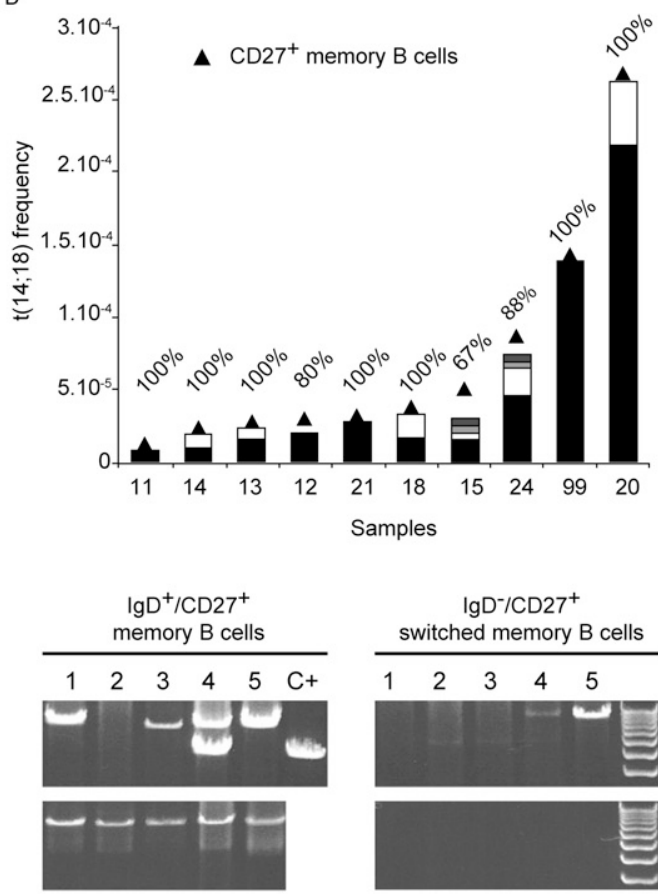

$\lg \mathrm{D}^{-} / \mathrm{CD} 27^{+}$

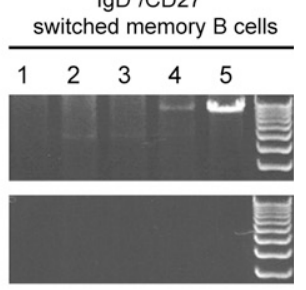

were isolated by cell sorting. Results from a representative cell-sorting experiment are shown. (B) Genomic DNA from the three purified subsets was tested for the presence of $t(14 ; 18)$ using the short-range $B C L 2 / J_{H}$ PCR assay (mbr20A/21A and $J_{H} \operatorname{coB} /$ cointB nested primers; see Fig. $1 \mathrm{~A}$ ). A two-step "fluctuation" nested PCR assay was used, consisting of at least 
and CSR activity (18), two mechanisms conferring a high propensity for further oncogenic aberrations in the context of accumulating genomic instability (e.g., BCL6/p53) (1, 19, $20)$. In this scenario, $t(14 ; 18)^{+}$cells in HI would constitute much more advanced precursors of the FL pathogenesis pathway than previously thought.

Based on our data, we propose a new model in which long-lived $\mathrm{t}(14 ; 18)^{+}$cells in peripheral blood of $\mathrm{HI}$ are mainly constituted by an atypical population of BCL2-rescued and incompletely maturated FL-like B cells released from the GCs (Fig. S2, http://www.jem.org/cgi/content/full/ jem.20061292/DC1). Interestingly, this incomplete maturation phenotype does not prevent FL to exit from the GC nor its spreading to other secondary organs, including lymph nodes and bone marrow $(16,21)$. Contrary to normal GC-derived B cells, FL clones are prone to intense trafficking between follicles $(3,22)$. Do the similar features of FL-like cells in HI confer the same migration properties, and similarly to $B C L 2-\mathrm{Tg}$ mice (17), allow the seeding of premalignant niches? The persistence and clonal expansion of $\mathrm{t}(14 ; 18)^{+}$follicular-like B cells over years in blood from HI $(6,8)$ goes along with the existence of niches, where follicular microenvironment might provide support for maintenance/proliferation in the context of polyclonal/chronic antigenic stimulation $(1,15,23,24)$. In support of this, hepatitus $\mathrm{C}$ virus patients, who display increased prevalence of $t(14 ; 18)$, show parallel regression of viral load and $t(14 ; 18)$ frequency in blood after antiviral therapy (25).

It remains fundamental to know if the rate of expanded FL-like cells in the peripheral blood of HI translates their activation status. Epidemiological studies have reported an increased prevalence of the $t(14 ; 18)$ associated with environmental exposures that might contribute to lymphomagenesis $(26,27)$. Further studies on the origin and status of the circulating FL-like B cells will thus be of prime importance, both to gain insights into disease progression and for the proper handling of $\mathrm{t}(14 ; 18)$ as an early biomarker of lymphoma.

\section{MATERIALS AND METHODS}

Patients and HI samples. Human samples were derived from three origins: 6 DNA samples from a cohort of $\mathrm{HI}(8)$, for which the presence of $\mathrm{t}(14 ; 18)$ translocation had been previously assessed on total PBMCs $(7,8) ; 10$ consecutive anonymous blood samples $(200-300 \mathrm{ml})$ from the local blood bank; 30 FL DNA samples from two independent sources previously described (28). Samples were collected after informed consent and approval by the local ethical committee (CCPPRB\# 99-07, France).

Antibodies. The following antibodies were used: IgD biotinylated, CD19APC (BD PharMingen), CD27-PE, CD20-FITC (Immunotech), and IgDFITC (Caltag Laboratories). Primary biotinylated antibody was revealed with Streptavidin-PerCP-Cy5.5 conjugate (BD PharMingen).

Cell separation and flow cytometry. PBMCs were isolated from peripheral blood by Ficoll-Hypaque density centrifugation (BD Biosciences); $\mathrm{B}$ cells were enriched to $>95 \%$ using the B cell negative isolation kit (Dynal). B-enriched cells were preincubated for 15 min with PBS-BSA-1\%-Azide$5 \%$ normal mouse serum and stained with either IgD biotinylated or IgDFITC, CD27-PE, and CD19-APC for $20 \mathrm{~min}$ at $+4^{\circ} \mathrm{C}$. After washing with PBS-1\% BSA-Azide and 15-min incubation with Streptavidin-PercPCy5.5, cells were analyzed on a FACScalibur (BD Biosciences). Cell sorting of (a) $\operatorname{IgD}^{+} / \mathrm{CD} 27^{-}$naive $\mathrm{B}$ cells, (b) $\mathrm{IgD}^{+} / \mathrm{CD} 27^{+} \operatorname{IgM}$ memory $\mathrm{B}$ cells, and (c) $\mathrm{IgD}^{-} / \mathrm{CD} 27^{+}$switched memory B cell subsets (11) was performed on a FACSAria (BD Biosciences). For all individuals, $\mathrm{IgD}^{+} \mathrm{CD} 27^{-}$and $\mathrm{IgD}{ }^{-} \mathrm{CD} 27^{+} \mathrm{B}$ cell subsets were sorted to $>98 \%$ purity, and the $\mathrm{IgD}{ }^{+} \mathrm{CD} 27^{+}$ $\mathrm{B}$ cell subset was sorted to $>95 \%$ purity. Isolated cells were then cryopreserved at $-80^{\circ} \mathrm{C}$ until DNA extraction. IgM- and IgD-only cells that represent only minor components (1-3\%) of the memory B cell pool were not sorted as single cells $(11,12)$.

Short-range PCR amplification of BCL2-IGH junctions. Total genomic DNA was prepared from PBMCs and/or sorted B cell subpopulations by the Qiagen DNA Blood Mini kit according to the manufacturer's instructions including RNase treatment (Qiagen). A two-step double-nested fluctuation PCR assay (8) was used to amplify BCL2/J $\mathrm{J}_{\mathrm{H}}$ junctions (Fig. $1 \mathrm{~A}$ and Table S1, available at http://www.jem.org/cgi/content/full/jem.20061292/DC1, for $\mathrm{mbr} 20 \mathrm{~A} / 21 \mathrm{~A}$ and $\mathrm{JHCo}-\mathrm{B} / \mathrm{Coint}-\mathrm{B}$ primers). As the frequency of $t(14 ; 18)$ junctions is low in PBMCs from HI, 5-10 reactions were performed in parallel using $100 \mathrm{ng}$ of DNA (per reaction) from each isolated B cell subpopulation. In the fluctuation range, at most one target molecule is present per PCR replicate, and if so will give rise to a detectable amplicon. The detection threshold of the assay is the function of the number of replicates performed with a constant amount of DNA per replicate (here, $2 \times 10^{-6}$ for $100 \mathrm{ng})$. The frequency of the event can then be calculated from the number of positive BCL2 $/ \mathrm{J}_{\mathrm{H}}$ amplicons using a Poisson's assumption (7). The primary PCR conditions were as follows: $30 \mathrm{~s}$ at $94^{\circ} \mathrm{C}, 30 \mathrm{~s}$ at $62^{\circ} \mathrm{C}$, and $1 \mathrm{~min}$ at $72^{\circ} \mathrm{C}, 40$ cycles. $1 \mu \mathrm{l}$ of each primary PCR reaction was used in the nested secondary PCR in the same conditions, except for 20 cycles. five parallel replicates performed for each sample (lanes 1-5). Results from sample \#20 using $100 \mathrm{ng}$ per replicate is depicted. (C) The contribution of naive ( $C D 27^{-}$, white circles) and memory $\left(\mathrm{CD} 27^{+}\right.$, black triangles) $B$ cells to the total $t(14 ; 18)^{+}$frequency $\left(C D 19^{+}\right.$, gray squares) in the healthy donors is shown. The translocation frequency in each subset was plotted for each donor (Table II). The 10 samples are ordered according to increasing $\mathrm{CD} 19^{+}$total B cell translocation frequencies (gray squares). (D) PCR fragments from $\mathrm{CD} 27^{+}$memory $B$ cells were cloned and sequenced, and clonality was identified on the basis of the BCL2/J junction, which is unique for a given translocation. The frequency of each independent BCL2/J $J_{H}$ clone was calculated, and the contribution of each clone (vertical bars, each color represents a given clone in a given sample) was superimposed on the $t(14 ; 18)$ frequency from the $\mathrm{CD} 27^{+}$ subset (black triangles). All positive amplicons were sequenced except one in sample \#12, three in \#15, and two in \#24 (percentage on top of histograms corresponds to the number of sequenced amplicons on the total number of positive replicates; Table II). For \#99, which required DNA dilution for the calculation of the frequency, 100\% corresponds to the sequencing of 10 out of 10 clones obtained from amplifications performed on diluted DNA (1:5; Table II) and undiluted DNA (9:9; not depicted). (E) BCL2-S $\gamma$ (top) and BCL2/S $\mu$ LR-PCR (bottom) were performed in the $3 \operatorname{lgD}{ }^{+} / C D 27^{-}$naive, $\lg \mathrm{D}^{+} / \mathrm{CD}_{2} 7^{+}$memory, and $\lg \mathrm{D}^{-} / \mathrm{CD} 27^{+}$ switched memory B cell subsets for four HI (\#15, \#20, \#21, and \#24). Results from sample \#24 are shown. $\beta$-globin/TCR- $\beta$ controls were performed as control for long-range amplifications (unpublished data). Most positive amplicons were confirmed by cloning/sequencing and alignment to germline $B C L 2, S \mu$, and $S \gamma$ loci (not depicted). Samples presenting multiple size bands revealed oligo/polyclonality. (F) The overall distribution of switched (gray histograms) versus unswitched (white histograms) translocated alleles in the three B cell subsets from samples $\# 15$, \#20, \#21, and \#24 is represented. The ratio of positive replicates is indicated at the top of the bars. 
Table II. Analysis of BCL2/J $\mathrm{J}_{H}$ translocations in total PBMCs and FACS-sorted B cell subsets from healthy donors

\begin{tabular}{|c|c|c|c|c|c|c|c|c|c|c|c|c|c|c|c|c|}
\hline \multirow{3}{*}{$\begin{array}{l}\text { Sample } \\
n=10\end{array}$} & \multicolumn{4}{|c|}{ PBMCs } & \multicolumn{4}{|c|}{$\operatorname{lgD}+/ C D 27^{-}$naive $B$ cells } & \multicolumn{4}{|c|}{$\lg D^{+} / \mathrm{CD} 27^{+}$memory $B$ cells } & \multicolumn{4}{|c|}{$\lg D^{-} / C D 27^{+}$switched memory $B$ cells } \\
\hline & Detection & Ratio & Frequency & $\%$ & Detection & Ratio & Frequency & $\%$ & Detection & Ratio & Frequency & $\%$ & Detection & Ratio & Frequency & $\%$ \\
\hline & & & & CD19+a & & & & & & & & & & & & \\
\hline 11 & yes & $1: 30$ & $2.1 \times 10^{-6}$ & 7.9 & no & $0: 10$ & $<1.1 \times 10^{-6}$ & 73 & yes & $1: 10$ & $6.6 \times 10^{-6}$ & 16 & yes & $0: 10$ & $<1.1 \times 10^{-6}$ & 7.5 \\
\hline 12 & no & $0: 30$ & $<1.1 \times 10^{-6}$ & 6.7 & yes & $3: 15$ & $1.4 \times 10^{-5}$ & 63.5 & yes & $3: 13$ & $1.6 \times 10^{-5}$ & 17 & yes & $2: 15$ & $8.9 \times 10^{-6}$ & 15 \\
\hline 13 & yes & $3: 60$ & $3.2 \times 10^{-6}$ & 4.9 & yes & $1: 10$ & $6.6 \times 10^{-6}$ & 57 & yes & $3: 10$ & $2.2 \times 10^{-5}$ & 28.5 & no & $0: 10$ & $<1.1 \times 10^{-6}$ & 10.5 \\
\hline 14 & yes & $2: 30$ & $4.3 \times 10^{-6}$ & 5.4 & yes & $1: 20$ & $3.2 \times 10^{-6}$ & 61 & yes & $5: 20$ & $1.8 \times 10^{-5}$ & 15 & no & $0: 20$ & $<1.1 \times 10^{-6}$ & 21 \\
\hline 15 & yes & $2: 30$ & $4.3 \times 10^{-6}$ & 6.6 & no & $0: 15$ & $<1.1 \times 10^{-6}$ & 50 & yes & $6: 15$ & $3.2 \times 10^{-5}$ & 23 & yes & $3: 15$ & $1.4 \times 10^{-5}$ & 23 \\
\hline 18 & yes & $1: 30$ & $2.1 \times 10^{-6}$ & 10 & no & $0: 5$ & $<1.1 \times 10^{-6}$ & 60 & yes & $2: 5$ & $3.2 \times 10^{-5}$ & 10 & no & $0: 5$ & $<1.1 \times 10^{-6}$ & 20 \\
\hline 20 & yes & $6: 30$ & $1.4 \times 10^{-5}$ & 5 & yes & $1: 5$ & $1.4 \times 10^{-5}$ & 72 & yes & $2: 5^{b}$ & $6.4 \times 10^{-5}$ & 10.6 & yes & $4: 5^{b}$ & $2 \times 10^{-4}$ & 15.5 \\
\hline 21 & no & $0: 30$ & $<1.1 \times 10^{-6}$ & 5 & no & $0: 5$ & $<1.1 \times 10^{-6}$ & 60 & yes & $1: 5$ & $1.4 \times 10^{-5}$ & 11 & yes & $1: 5$ & $1.4 \times 10^{-5}$ & 25 \\
\hline 24 & yes & $6: 30$ & $1.4 \times 10^{-5}$ & 10.1 & yes & $3: 20$ & $1.0 \times 10^{-5}$ & 46.5 & yes & $13: 20$ & $6.6 \times 10^{-5}$ & 19 & yes & $5: 20$ & $1.8 \times 10^{-5}$ & 39 \\
\hline $99^{c}$ & yes & $11: 30$ & $1.1 \times 10^{-5}$ & 4.9 & no & $0: 10$ & $1.1 \times 10^{-6}$ & 59 & yes & $1: 5^{\mathrm{d}}$ & $1.4 \times 10^{-4}$ & 37 & - & - & - & - \\
\hline Mean & & & $5.1 \times 10^{-6}$ & 6.6 & & & $5.3 \times 10^{-6}$ & 60.3 & & & $3.0 \times 10^{-5}$ & 17.8 & & & $2.9 \times 10^{-5}$ & 18.8 \\
\hline Total & $8: 10$ & & & & $5: 10$ & 9:105 & & & 9:9 & $36: 103$ & & & $6: 9$ & $15: 105$ & & \\
\hline [\%] & [80\%] & & & & [50\%] & {$[8.6 \%]^{\mathrm{e}}$} & & & [100\%] & {$[35 \%]^{\mathrm{e}}$} & & & [67\%] & {$[14 \%]^{e}$} & & \\
\hline
\end{tabular}

aDetermined by FACS.

${ }^{b}$ Positive replicates were out of the fluctuation range in the $\lg D^{+} / C D 27^{+}(4: 5)$ and $\lg D^{-} / C D 27^{+}(5: 5)$ fractions. PCR were performed on 50 ng DNA, and frequencies were calculated accordingly.

'B cell subsets were sorted only as $\lg D^{+} / C D 27^{-}$and $C D 19^{+} / C D 27^{+}$. \#99 was excluded from the calculations of the mean $t(14 ; 18)$ frequency.

dPositive replicates were out of the fluctuation range $(9: 9)$ in the $\mathrm{CD} 27^{+}$subset. PCR were performed on $10 \mathrm{ng}$ DNA, and frequencies were calculated accordingly.

eP values were determined by Pearson's $\chi^{2}$ test. Distributions of $\mathrm{BCL} 2 / J_{H}$ translocations in $\lg \mathrm{D}^{+} / \mathrm{CD} 27^{+}$memory $\mathrm{B}$ cells were statistically different from naive and switched memory $\mathrm{B}$ cells both in terms of detection rate in single individuals $(P=0.05)$ and of cumulative ratio of $B C L 2 / J_{H}$-positive replicates $\left(P<10^{-4}\right)$.

LR-PCR amplification of BCL2/C $\mu$ and BCL2/C $\gamma$ regions. For the amplification of BCL2/C $\mu$, the mbr20A/21A pair of nested forward primers was used in combination with a pair of nested reverse primers located in the $\mathrm{C} \mu$ and $\mathrm{S} \mu$ regions, respectively $\left(3^{\prime} \mathrm{C} \mu-1 \mathrm{~B} / 3^{\prime} \mathrm{S} \mu-2 \mathrm{~B}\right)$. For the amplification of BCL2/C $\gamma$, the same forward primers were used in combination with a pair of reverse nested consensus primers designed to hybridize to the $3^{\prime}$ flanking sequences of all $\mathrm{C} \gamma$ and $\mathrm{S} \gamma_{1-4}$ regions ( $3^{\prime} \mathrm{C} \gamma$ Cons-1B/3'S $\gamma$ Cons-2B). The same fluctuation PCR approach as for the short-range PCR assay was used (100 ng/replicate). Given the clonal nature of the tumor cells, a one-step standard LR-PCR approach was performed for FL patients. DNA extracted from all samples was controlled to be suitable for LR-PCR by performing the amplification of a $7.5-\mathrm{kb}$ fragment $\beta$-globin gene and an $11-\mathrm{kb}$ germline fragment of the TCR- $\beta$ locus. The following PCR conditions were used: $3 \mathrm{~min}$ at $95^{\circ} \mathrm{C}, 35$ cycles $\left(1 \mathrm{~min}\right.$ at $95^{\circ} \mathrm{C}, 12 \mathrm{~min}$ at $68^{\circ} \mathrm{C}$ ) and $10 \mathrm{~min}$ at $68^{\circ} \mathrm{C} .1 \mu \mathrm{l}$ of the primary LR-PCR was used in the double-nested LR-PCR performed in the same conditions, except for 20 cycles.

Analysis of BCL2/S $\boldsymbol{\mu}$ and BCL2/S $\gamma$ clones. PCR fragments were purified and cloned into the pGEM-T Easy Vector (Promega). Blunt-ended fragments generated by LR-PCR were purified and submitted to the Atailing procedure before cloning. The resulting clones were sequenced and analyzed using the BLASTn shareware (http://www.ncbi.nlm.nih.gov) and Vector NTI 9.0.0 sequence analysis software (Informax).

Statistical analysis. $\mathrm{p}$ values for $\mathrm{t}(14 ; 18)$-associated switch junctions analysis and analysis of $\mathrm{t}(14 ; 18)^{+}$cell distributions in peripheral $\mathrm{B}$ cell compartments were calculated by Fisher's exact test or chi-square test using STATA software (STATA corporation release 7.0). $\mathrm{p}$ values for $\mathrm{t}(14 ; 18)$ frequency were calculated by two-tailed Student's $t$ test.

Online supplemental material. Fig.S1 illustrates the set of LR-PCR data showing absence of CSR on the nonfunctional allele of the peripheral blood sIgM $/ \mathrm{D}^{+} \mathrm{CD} 27^{+} \mathrm{B}$ cell subset. Fig. S2 illustrates a reappraisal of the current model of FL pathogenesis. Table S1 describes the sequence of the PCR primers. Online supplemental material is available at http://www.jem. $\mathrm{org} / \mathrm{cgi} /$ content/full/jem.20061292/DC1.
We are grateful to J. Ewbank, U. Jäger, and R. Marculescu for helpful discussions. We are grateful to the Division of Hematology, Medical University of Vienna (Vienna, Austria) for providing the FL DNA samples. We thank C. Beziers-Guigue for help with illustrations. We also thank N. Brun, M. Barad, M. Briand, and Y. Lecluse for technical assistance.

This work was supported by grant no. INE2003114116 from la Fondation pour la Recherche Médicale, grant nos. 7877 and 3618 from the Association pour la Recherche sur le Cancer (ARC), a grant from Le Conseil Général des Bouches du Rhône, and institutional grants from INSERM and CNRS. This study was also supported by grants from la Ligue Nationale contre le Cancer (comité de la Manche), Conseil Général du Calvados, and Université de Caen Basse-Normandie. Work in the lab of B. Nadel is supported by the AVENIR2003 grant from INSERM. $S$. Roulland is a recipient of the Young Investigators Program from INSERM. B. Montpellier is a recipient of a fellowship from la Ligue Nationale Contre le Cancer. B. Nadel is a recipient of a Contrat d'Interface INSERM/Assistance PubliqueHôpitaux de Marseille.

The authors have no conflicting financial interests.

\section{Submitted: 19 June 2006}

Accepted: 27 September 2006

\section{REFERENCES}

1. Kuppers, R. 2005. Mechanisms of B-cell lymphoma pathogenesis. Nat. Rev. Cancer. 5:251-262.

2. McDonnell, T.J., N. Deane, F.M. Platt, G. Nunez, U. Jaeger, J.P. McKearn, and S.J. Korsmeyer. 1989. bcl-2-immunoglobulin transgenic mice demonstrate extended B cell survival and follicular lymphoproliferation. Cell. 57:79-88.

3. Cong, P., M. Raffeld, J. Teruya-Feldstein, L. Sorbara, S. Pittaluga, and E.S. Jaffe. 2002. In situ localization of follicular lymphoma: description and analysis by laser capture microdissection. Blood. 99: 3376-3382.

4. Egle, A., A.W. Harris, M.L. Bath, L. O’Reilly, and S. Cory. 2004. VavP-Bcl2 transgenic mice develop follicular lymphoma preceded by germinal center hyperplasia. Blood. 103:2276-2283.

5. Limpens, J., R. Stad, C. Vos, C. de Vlaam, D. De Jong, G.J. van Ommen, E. chuuring, and P.M. Kluin. 1995. Lymphoma-associated translocation $\mathrm{t}(14 ; 18)$ in blood B cells of normal individuals. Blood. $85: 2528-2536$. 
6. Dolken, G., G. Illerhaus, C. Hirt, and R. Mertelsmann. 1996. BCL-2/JH rearrangements in circulating $\mathrm{B}$ cells of healthy blood donors and patients with nonmalignant diseases. J. Clin. Oncol. 14:1333-1344.

7. Roulland, S., P. Lebailly, G. Roussel, M. Briand, D. Cappellen, D. Pottier, A. Hardouin, X. Troussard, C. Bastard, M. Henry-Amar, and P. Gauduchon. 2003. BCL-2/JH translocation in peripheral blood lymphocytes of unexposed individuals: lack of seasonal variations in frequency and molecular features. Int. J. Cancer. 104:695-698.

8. Roulland, S., P. Lebailly, Y. Lecluse, N. Heutte, B. Nadel, and P. Gauduchon. 2006. Long-term clonal persistence and evolution of $\mathrm{t}(14 ; 18)-$ bearing B cells in healthy individuals. Leukemia. 20:158-162.

9. Vaandrager, J.W., E. Schuuring, H.C. Kluin-Nelemans, M.J. Dyer, A.K. Raap, and P.M. Kluin. 1998. DNA fiber fluorescence in situ hybridization analysis of immunoglobulin class switching in B-cell neoplasia: aberrant $\mathrm{CH}$ gene rearrangements in follicle center-cell lymphoma. Blood. 92:2871-2878.

10. Akasaka, T., H. Akasaka, N. Yonetani, H. Ohno, H. Yamabe, S Fukuhara, and M. Okuma. 1998. Refinement of the BCL2/immunoglobulin heavy chain fusion gene in $\mathrm{t}(14 ; 18)(\mathrm{q} 32 ; \mathrm{q} 21)$ by polymerase chain reaction amplification for long targets. Genes Chromosomes Cancer. 21:17-29.

11. Klein, U., K. Rajewsky, and R. Kuppers. 1998. Human immunoglobulin (Ig) $\mathrm{M}^{+} \mathrm{IgD}^{+}$peripheral blood B cells expressing the CD27 cell surface antigen carry somatically mutated variable region genes: CD27 as a general marker for somatically mutated (memory) B cells. J. Exp. Med. 188:1679-1689.

12. Weller, S., M.C. Braun, B.K. Tan, A. Rosenwald, C. Cordier, M.E. Conley, A. Plebani, D.S. Kumararatne, D. Bonnet, O. Tournilhac, et al. 2004. Human blood IgM "memory" B cells are circulating splenic marginal zone B cells harboring a prediversified immunoglobulin repertoire. Blood. 104:3647-3654.

13. Kruetzmann, S., M.M. Rosado, H. Weber, U. Germing, O. Tournilhac, H.H. Peter, R. Berner, A. Peters, T. Boehm, A. Plebani, et al. 2003. Human immunoglobulin M memory B cells controlling Streptococcus pneumoniae infections are generated in the spleen. J. Exp. Med. 197:939-945.

14. Ma, C.S., S. Pittaluga, D.T. Avery, N.J. Hare, I. Maric, A.D. Klion, K.E. Nichols, and S.G. Tangye. 2006. Selective generation of functional somatically mutated IgM+CD27+, but not Ig isotype-switched, memory B cells in X-linked lymphoproliferative disease. J. Clin. Invest. 116:322-333.

15. Zelenetz, A.D., T.T. Chen, and R. Levy. 1992. Clonal expansion in follicular lymphoma occurs subsequent to antigenic selection. J. Exp. Med. 176:1137-1148.

16. Harris, N.L., E.S. Jaffe, H. Stein, P.M. Banks, J.K. Chan, M.L. Cleary, G. Delsol, C. Wolf-Peeters, B. Falini, and K.C. Gatter. 1994. A revised
European-American classification of lymphoid neoplasms: a proposal from the International Lymphoma Study Group. Blood. 84:1361-1392.

17. McDonnell, T.J., and S.J. Korsmeyer. 1991. Progression from lymphoid hyperplasia to high-grade malignant lymphoma in mice transgenic for the $\mathrm{t}(14 ; 18)$. Nature. 349:254-256.

18. Greeve, J., A. Philipsen, K. Krause, W. Klapper, K. Heidorn, B.E. Castle, J. Janda, K.B. Marcu, and R. Parwaresch. 2003. Expression of activation-induced cytidine deaminase in human B-cell non-Hodgkin lymphomas. Blood. 101:3574-3580.

19. Ramiro, A.R., M. Jankovic, T. Eisenreich, S. Difilippantonio, S. Chen-Kiang, M. Muramatsu, T. Honjo, A. Nussenzweig, and M.C. Nussenzweig. 2004. AID is required for $\mathrm{c}-\mathrm{myc} / \mathrm{IgH}$ chromosome translocations in vivo. Cell. 118:431-438.

20. Ramiro, A.R., M. Jankovic, E. Callen, S. Difilippantonio, H.T. Chen, K.M. McBride, T.R. Eisenreich, J. Chen, R.A. Dickins, S.W. Lowe, et al. 2006. Role of genomic instability and p53 in AID-induced c-mycIgh translocations. Nature. 440:105-109.

21. Bognar, A., B. Csernus, C. Bodor, L. Reiniger, A. Szepesi, E. Toth, L. Kopper, and A. Matolcsy. 2005. Clonal selection in the bone marrow involvement of follicular lymphoma. Leukemia. 19:1656-1662.

22. Oeschger, S., A. Brauninger, R. Kuppers, and M.L. Hansmann. 2002 Tumor cell dissemination in follicular lymphoma. Blood. 99:2192-2198.

23. Vinuesa, C.G., S.G. Tangye, B. Moser, and C.R. Mackay. 2005 Follicular B helper $\mathrm{T}$ cells in antibody responses and autoimmunity. Nat. Rev. Immunol. 5:853-865.

24. Bernasconi, N.L., E. Traggiai, and A. Lanzavecchia. 2002. Maintenance of serological memory by polyclonal activation of human memory B cells. Science. 298:2199-2202.

25. Giannelli, F., S. Moscarella, C. Giannini, P. Caini, M. Monti, L. Gragnani, R.G. Romanelli, V. Solazzo, G. Laffi, G. La Villa, et al. 2003. Effect of antiviral treatment in patients with chronic HCV infection and $\mathrm{t}(14 ; 18)$ translocation. Blood. 102:1196-1201.

26. Roulland, S., P. Lebailly, Y. Lecluse, M. Briand, D. Pottier, and P. Gauduchon. 2004. Characterization of the t(14;18) BCL2-IGH translocation in farmers occupationally exposed to pesticides. Cancer Res. 64:2264-2269.

27. Chiu, B.C., B.J. Dave, A. Blair, S.M. Gapstur, S.H. Zahm, and D.D. Weisenburger. 2006. Agricultural pesticide use and risk of $t(14 ; 18)$ defined subtypes of non-Hodgkin lymphoma. Blood. 108:1363-1369.

28. Jager, U., S. Bocskor, T. Le, G. Mitterbauer, I. Bolz, A. Chott, M. Kneba, C. Mannhalter, and B. Nadel. 2000. Follicular lymphomas' BCL-2/IgH junctions contain templated nucleotide insertions: novel insights into the mechanism of $\mathrm{t}(14 ; 18)$ translocation. Blood. 95:3520-3529.

29. Chaudhuri, J., and F.W. Alt. 2004. Class-switch recombination: interplay of transcription, DNA deamination and DNA repair. Nat. Rev. Immunol. 4:541-552. 